\title{
The association between diabetes mellitus and urinary incontinence in adult women
}

\author{
Yenal Izci • Pınar Topsever • T. Müge Filiz • \\ Nursan Dede Çınar • Cefariye Uludağ • \\ Toine Lagro-Janssen
}

Received: 20 January 2009/Accepted: 29 March 2009/Published online: 30 April 2009

(C) The Author(s) 2009. This article is published with open access at Springerlink.com

\begin{abstract}
Introduction and hypothesis The purpose of the study was to investigate the relationship of diabetes mellitus and urinary incontinence in adult women.

Methods We conducted a cross-sectional, comparative study with a case-control design. One thousand three hundred eighty-one women (aged 20-87 years) attending six Primary Healthcare Centers in Turkey were enrolled in this study, after giving their informed consent. Subjects were dichotomized into cases and controls according to presence of diabetes mellitus (DM) and were matched for the confounding factors age, body mass index (BMI), and reproductive history.

Results Nine hundred ten women were included: 273 diabetics and 637 non-diabetics. Diabetes was shown to be associated with a 2.5 -fold risk increase for urinary incontinence (UI), and age and BMI were weakly associated with UI. UI was significantly more prevalent in diabetic women: $41 \%$ diabetic and $22.1 \%$ non-diabetic
\end{abstract}

Y. Izci $\cdot$ T. Lagro-Janssen $(\bowtie)$

Department Primary Care and Community Care,

Centre for Family Medicine, Geriatric Care and Public Health,

Women Studies Medicine, 117,

P.O. Box 9101, 6500 HB Nijmegen, The Netherlands

e-mail: a.lagro-janssen@elg.umcn.nl

P. Topsever · T. M. Filiz

Department of Family Medicine, Faculty of Medicine,

Kocaeli University,

Kocaeli, Turkey

N. D. Çınar $\cdot$ C. Uludağ

College of Nursing, Sakarya University,

Adapazarı, Turkey women reported UI $(p<0.001)$. Age, BMI, and DM were revealed as independent determinants of UI in adult women. Urge incontinence was more prevalent in nondiabetic women, whereas stress and mixed incontinence were more prevalent among diabetic women.

Conclusions DM is the most important independent determinant of UI.

Keywords Urinary incontinence - Diabetes mellitus . General practice $\cdot$ Women $\cdot$ Primary care

\section{Introduction}

Diabetes mellitus (DM) is a worldwide health problem with rising prevalence. These rising numbers of prevalence are contributable to a change in life style, increasing obesity rates, and aging of the population [1]. DM is a chronic disease, which can lead to important complications like neuropathy, retinopathy, and nephropathy. It is therefore important to understand that rising numbers of diabetes can result in higher incidence of diabetic complications, which in turn have to be prevented.

Recent studies have shown that urinary incontinence (UI) among adult women has also rising prevalence and incidence, especially with higher age [2-5]. In epidemiological studies, prevalence of UI among adult women in Turkey was reported as $25.8 \%, 23.9 \%$, and $20.8 \%$ [6-8]. Previous studies have shown that women with UI can experience social isolation, psychosocial stress, and decreased quality of life $[3,6,9]$. In order to prevent UI in $\mathrm{DM}$, we need to identify the etiology of UI as a comorbidity in DM [10-19]. The etiology of UI is not well understood yet, but research mainly suggests that the same mechanisms as in diabetic microvascular complications 
contribute to it [20]. Therefore, it is necessary to distinguish the different types of UI because they have different etiologies. Evidence suggests that urge incontinence can be caused by microvascular damage due to DM leading to alterations in detrusor muscle function, innervation, and function of the neuronal component [20-22], whereas stress UI is due to dysfunction of the striated muscle of the urethral sphincter and pelvic floor muscles and their innervation [24]. Causes of stress UI are pregnancy, delivery conditions (weight of baby, length of second active stage labor, and instrumental delivery), and being overweight. Mixed UI is a combination of both health conditions together [23].

According to the etiological factors, DM does not seem to contribute much to the development of stress UI. Most studies $[14,15,21,22]$ support the idea that DM plays particularly a role in Urge UI due to glycosuria, detrusor overactivity, recurrent urinary tract infections, and diabetic cystopathy. But, a recent hypothesis states that DM and obesity are linked with each other and that this combination leads to higher stress UI rates due to increased intraabdominal and pelvic pressure $[11,12,16]$.

Diabetes mellitus is preventable by lifestyle interventions like exercise and diet $[1,17]$. Some research suggests that nearly $50 \%$ of severe incontinence could be avoided by preventing type $2 \mathrm{DM}[11,24]$. This emphasizes that there is an important link between both health conditions. Research about epidemiology, etiology, and risk factors of UI is therefore very important in family medicine. Prior research on this field gained useful information about prevalence and risk factors. DM is one of the identified risk factors together with age, body mass index (BMI), reproductive history, smoking, recurrent urinary tract infections, chronic cough, and other chronic diseases and childhood enuresis [5, 15, 18-20, 25]. But, evident information about independent risk factors and especially $\mathrm{DM}$ as an independent risk factor for UI is still lacking.

Therefore, we hypothesized that UI in adult women is more frequent in diabetic women irrespective of confounding factors. The aim of this study is to compare the prevalence of UI between diabetic and non-diabetic adult women who are similar with respect to other known risk factors. In addition, factors related to and interacting with the presence of UI in diabetic and non-diabetic adult women were investigated. The identification of such modifiable factors is important for improving preventive care strategies in general practice.

\section{Materials and methods}

We conducted a cross-sectional, comparative study with a case-control design at six randomly selected Primary
Healthcare Centers ("Saglik Ocaklari”, three central and three peripheral with 32.632 registered women $>20$ years, 15.070 central and 17.562 peripheral) in the Western Marmara region of Kocaeli and Sakarya, Turkey. All women aged 20 years and over attending these PHCs were asked for data acquisition with help of a questionnaire. Data collection was between September 2005 and March 2008, and 1,381 women were enrolled non-consecutively in the study after their verbal informed consent. All gained information concerning these women was put into a database, and according to these data, women were divided in diabetics (cases) and non-diabetics (controls). The presence of diabetes mellitus was defined as patient reported diagnosis, verified from patient records as well as taking anti-diabetic medication. The diabetic group was then matched for plausible confounders for UI like age, BMI, and reproductive history with the control group. This was performed manually by selecting for each diabetic woman two or three non-diabetic women, who were similar with respect to age, BMI, and reproductive history. This matching process yielded two comparative groups, which is needed to perform correct data analysis on the role of diabetes mellitus.

The participants completed a comprehensive questionnaire consisting of two parts. The first part was investigating personal medical history, including reproductive history (variables were grouped in an ordinal fashion according to number of gravidity or parity, respectively: $0=$ none, $1=$ one, $2=$ two, $3=$ three and $4=$ four or more); anthropometric measures like body weight (in kilograms) and height (in meters) used for BMI calculation $\left(\mathrm{kg} / \mathrm{m}^{2}\right)$; lifestyle factors like smoking, alcohol-tea-coffee consumption; medical history data like operations (abdominal wall or vaginal), chronic diseases, medication, and - for diabetic individuals - diabetes treatment (diet, exercise, tablet, and/or insulin medication), fasting blood glucose, $\mathrm{HbA}_{1 \mathrm{C}}$, total cholesterol, triglycerides, HDL, LDL, blood pressure, albumin, and diabetic complications (retinopathy, nephropathy, neuropathy, and diabetic foot).

The second part of the questionnaire was including specific questions about urinary incontinence.

UI was determined if the women affirmatively answered the question about "any kind of involuntary loss of urine" $[9,13]$. Frequency of leakage $(1=$ less than once a month, $2=$ one or several times a month, $3=$ one or several times a week, $4=$ every day and/or night), amount of leakage each time $(1=$ drops or little, $2=$ sometimes enough for changing underwear, $3=$ so much that using "pads" is necessary), and circumstance of leakage (coughing, sneezing, laughing, on effort/physical exertion, during sexual intercourse, washing hands, with a sudden and strong urge to void) [9] were used for categorizing stress, urge, or mixed UI. 
Table 1 General characteristics of the study population

\begin{tabular}{llll}
\hline & Diabetics & Non-diabetics & $p$ value \\
\hline Age (years) & $50.75 \pm 9.18$ & $49.83 \pm 9.10$ & 0.164 \\
BMI $\left(\mathrm{kg} / \mathrm{m}^{2}\right)$ & $27.60 \pm 4.45$ & $27.45 \pm 4.57$ & 0.642 \\
FPG $(\mathrm{mg} / \mathrm{dL})$ & $145.34 \pm 42.85$ & - & - \\
SBP $(\mathrm{mmHg})$ & $129.23 \pm 13.90$ & - & - \\
DBP $(\mathrm{mmHg})$ & $76.38 \pm 8.53$ & - & - \\
Oral anti-diabetic users & 168 & - & - \\
Insulin using diabetics & 37 & - & - \\
\hline
\end{tabular}

$F P G$ fasting plasma glucose, $S B P$ systolic blood pressure, $D B P$ diastolic blood pressure

SPSS version 15.0 was used for statistical analysis. Except for descriptives (mean $\pm \mathrm{SD}, \%$ ), independent samples $t$ test and Chi-square test were used for comparisons of parametric and non-parametric variables, respectively; odds ratios were calculated via cross-tabulation, and binary logistic regression analysis was performed with UI as dependent and DM and other confounding variables of interest as covariates to identify independent determinants of UI. Statistical significance was set at 0.05 with a confidence interval (CI) of $95 \%$. Interaction terms were built for DM and age, BMI as well as, gravidity and parity (significance level for $P$ interaction $<0.1$ ).

\section{Results}

Characteristics of the study population

The study population consisted of 910 women, which means that 471 women were excluded after matching for confounders. The included women had a mean age of 50 years; most women were obese (mean BMI 27.5), married, first school graduates, and had more than two deliveries. Most of the diabetic women were normotensive and were on oral anti-diabetic agents.

The population was divided according to the presence of diabetes mellitus into 273 cases and 637 controls. Cases and controls were similar with respect to age, BMI, and reproductive history (number of gravidities and parities; Table 1).

Gravidity and parity numbers were grouped in an ordinal fashion as mentioned above. The distribution of these
Table 3 Independent determinants of UI

\begin{tabular}{lcc}
\hline & $p$ value & Odds ratio with $95 \% \mathrm{CI}$ \\
\hline Age & 0.016 & $1.02(1.00-1.04)$ \\
BMI & 0.000 & $1.07(1.04-1.11)$ \\
Diabetes & 0.000 & $2.46(1.80-3.36)$ \\
\hline
\end{tabular}

confounding factors for case and control group was similar (not shown).

Prevalence of UI by presence of diabetes mellitus

Urinary incontinence was significantly more prevalent in diabetic women with an odds ratio of 2.5 (95\% confidence Interval $=1.8-3.3$; Table 2).

Determinants of UI—general

Binary logistic regression analysis with UI as dependent and plausible confounding factors as covariates revealed age, BMI, and the presence of DM as independent determinants of UI. Table 3 shows the significance levels and odds ratios for these determinants.

Determinants of UI-within DM study population

We also compared the fasting plasma glucose (FPG) levels among the continent and incontinent diabetic women in order to find a correlation between the presence of UI and the level of FPG. Although there was a numeric difference in favor of incontinent diabetic women, FPG levels were similar in both groups.

\section{Types of UI and DM}

Urge UI, stress UI, and mixed UI were seen in 47 (5.2\%), $61(6.7 \%)$, and $145(15.9 \%)$, respectively (on a total population of $n=910$ ). The percentages of the types among diabetics and non-diabetics are shown in Table 4.

Comparing the types of incontinence frequencies among the diabetics and non-diabetics of the incontinent population ( $n=112$ and $n=141$, respectively) shows that urge UI is more prevalent in non-diabetic women, and stress and mixed UI are more prevalent in diabetic women.
Table 2 Prevalence of UI by presence of DM

\begin{tabular}{|c|c|c|c|c|}
\hline & \multicolumn{2}{|c|}{ Urinary incontinence } & \multirow[t]{2}{*}{$p$ value } & \multirow[t]{2}{*}{ Odds ratio } \\
\hline & No & Yes & & \\
\hline Diabetics & $161(59.0 \%)$ & $112(41.0 \%)$ & $<0.001$ & $2.45(95 \%$ CI $1.80-3.32)$ \\
\hline Non-diabetics & $496(77.9 \%)$ & $141(22.1 \%)$ & & \\
\hline
\end{tabular}


Table 4 Distribution of UI types according to numbers of cases and controls

\begin{tabular}{lcc}
\hline & Diabetics $(n, \%)$ & Non-diabetics $(n, \%)$ \\
\hline Urge incontinence & $11(9.8 \%)$ & $36(25.5 \%)$ \\
Stress incontinence & $31(27.7 \%)$ & $30(21.3 \%)$ \\
Mixed incontinence & $70(62.5 \%)$ & $75(53.2 \%)$ \\
\hline
\end{tabular}

Pearson $\chi^{2}$ test: $p=0.006$

The presence of UI by interactions of determinants

Univariate analysis for regression was performed with UI as dependent variable, DM as random factor, and age, BMI, gravidity, and parity numbers as covariates to identify possible interacting factors, for those confounders that remained in the model. A custom univariate model was built as shown in Table 5, and significance was set as $P$ interaction $<0.1$.

The only significant interaction of determinants for the presence of UI was shown to be between BMI and DM.

\section{Discussion}

Results and comparisons

The most important finding of our study is that diabetes mellitus is an independent risk factor for urinary incontinence. Diabetic women in our study population had a 2.5fold increased risk for UI compared with non-diabetic women. It is to our knowledge the first time that DM is shown so evident to associate independently with urinary incontinence. Previous comparable studies produced lower odds ratios [14, 16, 25] and relative risks [10], respectively.

Most studies point out BMI and age as risk factors for UI. Higher BMI goes along with a higher intrapelvic pressure, which can lead to urinary incontinence, but is a modifiable risk factor [14, 25]. Evidence suggests that weight loss reduces intraabdominal and intravesicular pressure, which leads to reduced urethral mobility, and this seems to reduce risk and episodes of stress and urge UI [13, $14,24]$. The unmodifiable risk factor higher age also goes along with a higher risk for and prevalence of UI $[14,19]$. Although age and BMI in our study also were significantly associated with urinary incontinence, the effect size was too small to translate into clinical significance.

The reason for this low effect size of age and BMI is that cases and controls in our study were similar with respect to these confounding factors.

The prevalence of UI among diabetics and non-diabetics was $41.0 \%$ and $22.1 \%$, respectively. Prevalence numbers in comparable studies for cases and controls respectively were similar: $35.4-16.8 \%$ [4] and 39-29\% [15]. We cannot give a general prevalence percentage in our study population because we matched our group for confounding factors. Our prevalence rate for the whole group would therefore be biased and probably higher than comparable national prevalence studies [6-8].

The distribution of UI types among diabetic women is an unexpected finding. Urge incontinence is significantly less pronounced in diabetic women, where we would expect that it should be more prevalent because of the diabetic microvascular damage involvement in its etiology. Although we do not have any information on duration of DM (see "Limitations of the study"), it can be argued that most diabetic women were not in an advanced stage of the condition because of the high proportion of oral antidiabetic therapy. This conclusion might also be biased because there is a proven underuse of insulin therapy worldwide. In that case especially, diabetic microvascular complications are not expected to be very prevalent because they are more likely to occur after prolonged disease duration of more than 8 years according to the "ADA consensus committee report references" [16].

This means that in our study population most UI in diabetic women is a result of mechanic stress and an increased abdominal and pelvic pressure. This is partially proved by the higher amount of stress UI. We expect that the predominance in mixed incontinence is also due to the higher numbers of stress UI.

The univariate analysis for regression unveiled an interaction between diabetes mellitus and BMI, meaning that the association between UI and DM is higher if diabetic women are more overweight and less pronounced if diabetic women have lower BMI. This finding is supported by other research [5], indicating that as much as $80 \%$ of type II DM can be attributed to obesity. The interaction between DM and BMI is also supporting the hypothesis in our "Introduction" that the combination of DM and obesity leads to an increased intraabdominal pressure and as a consequence to stress incontinence. In the present sample, overweight and obesity rather than metabolic disturbances (DM) seemed to be predominant in the etiology of UI, which is mirrored in the general high proportion of stress and mixed UI.

Table 5 Presence of UI by interactions of determinants

\begin{tabular}{lc}
\hline Possible interactions & $P$ interaction \\
\hline Age $\times \mathrm{DM}$ & 0.831 \\
$\mathrm{BMI} \times \mathrm{DM}$ & 0.003 \\
Gravidity nr $\times \mathrm{DM}$ & 0.450 \\
Parity $\mathrm{nr} \times \mathrm{DM}$ & 0.159 \\
\hline
\end{tabular}


Limitations of the study

There are some limitations with respect to data source and availability as well as study design to this study, which should be taken into consideration when interpreting the results and which are discussed in the context of the medical literature below.

\section{Self-reported data}

The following items were assessed according to information directly obtained from the participants:

- Self-reported urinary incontinence: As reported in previous research [3, 5], women are not always willing to talk about UI and might hide their problems. Suggested reasons for this are embarrassment, underestimating the problem, and thinking it is normal or goes along with aging $[3,5,26]$. However, this could be expected for all women in the study of diabetics and non-diabetics so we do not think that this influenced our results. But, literature says that this can result in underestimation of the risk of incontinence associated with DM [10,22]. We also consider that this could lead to lack of objective data on amount of leakage, and this could be approved in further studies by examining the presence of prolapses and by urodynamic testing.

- Self-reported diabetes mellitus: Although this condition was self-reported to diagnosis, fasting plasma glucose, $\mathrm{HbA}_{1 \mathrm{C}}$, and systolic and diastolic blood pressure were verified from patient records as much as possible. Another possible limitation concerning diabetic cases is the possibility that some participants have undiagnosed or missed DM. This can cause bias toward the null; this means that the true relationship between DM and risk of UI may be somewhat greater than our results do estimate [10].

- A previous research also suggests that self-reported length and weight typically results in underestimation of BMI. This means that the effect of BMI in the study population may actually be higher than our analysis indicates [3].

\section{Lack of data on diabetes mellitus}

The severity and duration of diabetes mellitus could not be determined in our analysis. Although questions about $\mathrm{HbA}_{1 \mathrm{C}}$, total cholesterol, triglycerides, HDL, LDL, blood pressure, albumin, and diabetic complications (retinopathy, nephropathy, neuropathy, and diabetic foot) were present in our questionnaire, data on these fields were lacking and were not suitable for statistical analysis.

Literature points out that more advanced DM goes along with higher risk of (urge) UI [10, 12, 16, 22], as we suggested above in our discussion about Table 4.
In $\mathrm{DM}$, the follow-up parameter for long-term glycemic control is $\mathrm{HbA}_{1 \mathrm{C}}$. We collected data in primary care facilities where $\mathrm{HbA}_{1 \mathrm{C}}$ measurements are not always possible. In the IDF Diabetes Guideline, A1c levels for glycemic follow-up are recommended according to the level of development of diabetes care in the countries and health care settings. The present data included cross-sectional FPG levels only, which did not show any association with UI.

\section{Study design}

A cross-sectional study design is not able to draw causal conclusions. Nevertheless, the present findings constitute the rationale for further research on the importance of diabetes' role in UI. The role of two factors contributing to the development of UI, namely mechanic stress (especially gravidities, parities, and obesity) for stress UI and metabolic stress (especially hyperglycemia in bladder pathophysiology) should be investigated further in prospective studies in order to determine the etiology of UI.

\section{Further implications}

Considering that such research can take up decennia, we would like to conclude with some recommendations based on our results. Primary healthcare is aiming to improve community health by health promotion as risk factor prevention and prevention of diseases and complications. Management of DM is also based on prevention in high-risk and prediabetic individuals, prevention of complications as summed up above, and is mostly about lifestyle intervention, diet regimens, and exercise. According to our results, we can conclude that diabetes mellitus is an unarguable independent risk factor for urinary incontinence and that the interaction between DM and BMI seems to be important for stress UI. Therefore, we suggest that all diabetic patients should be questioned for UI in DM long-term management in order to prevent this problem. The importance of UI should also be emphasized in health promotion in overweight and obesity in diabetic and non-diabetic women.

\section{Conflicts of interest None.}

Open Access This article is distributed under the terms of the Creative Commons Attribution Noncommercial License which permits any noncommercial use, distribution, and reproduction in any medium, provided the original author(s) and source are credited.

\section{References}

1. Tuomelihto J, Lindström J, Eriksson JG et al (2001) Prevention of type 2 diabetes mellitus by changes in lifestyle among subjects with impaired glucose tolerance. N Engl J Med 344:1343-1350 
2. Teunissen D, van Weel C, Lagro-Janssen T (2005) Urinary incontinence in older people living in the community: examining help-seeking behavior. Br J Gen Pract 55:776-782

3. Teunissen D, van den Bosch W, van Weel C, Lagro-Janssen $T$ (2006) "It can always happen": the impact of urinary incontinence on elderly men and women. Scan J Prim Health Care 24: 166-173

4. Hunskaar S, Lose G, Sykes D, Voss S (2004) The prevalence of urinary incontinence in women in four European countries. Br J Urol 93:324-330

5. Minassian VA, Drutz HP, Al-Badr A (2003) Urinary incontinence as a worldwide problem. Int J Gynaecol Obstet 82:327-338

6. Ozerdogan N, Beji NK, Yalcin O (2004) Urinary incontinence: its prevalence, risk factors and effects on the quality of life of women living in a region of Turkey. Gynecol Obstet Invest 58:145-50 (Abstract only)

7. Kocak I, Okyay P, Dundar M, Erol H, Beser E (2005) Female urinary incontinence in the west of Turkey: prevalence, risk factors and impact on quality of life. Eur Urol 48:634-41

8. Maral I, Ozkardes H, Peskircioglu L, Bumin MA (2001) Prevalence of stress urinary incontinence in both sexes at or after age 15 years: a cross-sectional study. J Urol 165:408-12

9. Filiz TM, Topsever P, Uludag C, Gorperioglu S, Cinar N (2007) Effects of age and urinary incontinence severity on generic SF-36 quality of life measurements in Sakarya, Turkey. Turk Klin J Med Science 27:189-194

10. Lifford KL, Curhan GC, Hu FB, Barbiere RL, Grodstein F (2005) Type 2 diabetes mellitus and risk of developing urinary incontinence. J Am Geriatr Soc 53:1851-1857

11. Brown JS (2005) Urinary incontinence: an important and underrecognized complication of type 2 diabetes mellitus. J Am Geriatr Soc 53:2028-2029

12. Jackson SL, Scholes D, Boyko EJ, Abraham L, Fihn SD (2005) Urinary incontinence and diabetes in postmenopausal women. Diabetes Care 28(7):1730-1738

13. Brown JS, Vittinghoff E, Lin F, Nyberg LM, Kusek JW, Kanaya AM (2006) Prevalence and Risk factors of urinary incontinence in women with type 2 diabetes and impaired fasting glucose. Diabetes Care 26(6):1307-1312

14. Smith DB (2006) Urinary incontinence and diabetes (review). J WOCN 33(6):619-623
15. Ebbesen MH, Hannestad YS, Midthjell K, Hunskaar S (2007) Diabetes and urinary incontinence - prevalence data from Norway. Acta Obstet Gynecol Scan 86:1256-1262

16. Lewis CM, Schrader R, Many A, Mackay M, Rogers RG (2005) Diabetes and urinary incontinence in 50- to 90-year-old women: a cross-sectional population-based study. Am J Obstet Gynecol 193:2154-2158

17. Brown JS, Wing R, Barrett-Connor E, Nyberg LM, Kusek JW, Orchard TJ et al (2006) Lifestyle intervention is associated with lower prevalence of urinary incontinence - the diabetes prevention program. Diabetes Care 29:385-390

18. Danforth KN, Townsend MK, Lifford K, Curhan GC, Resnick NM, Grodstein F (2006) Risk factors for urinary incontinence among middle-aged women. Am J Obstet Gynecol 194:339-345

19. van Gerwen M, Schellevis F, Lagro-Janssen ALM (2007) Comorbidities associated with urinary incontinence: a casecontrol study from the Second Dutch National Survey of General Practice. JABFM 20:608-610

20. Kuh D, Cardozo L, Hardy R (1999) Urinary incontinence in middle aged women: childhood enuresis and other lifetime risk factors in a British prospective cohort. J Epidemiol Community Health 53:453-458

21. Kebapci N, Yenilmez A, Efe B, Entok E, Demirustu C (2007) Bladder dysfunction in type 2 diabetic patients. Neurourol Urodyn 26:814-819

22. Hill SR, Fayyad AM, Jones GR (2008) Diabetes mellitus and female lower urinary tract symptoms: a review. Neurourol Urodyn 27(5):362-7

23. Haslam J (2006) Stress urinary incontinence, whose problem is it? J Community Nurs 20:17-20

24. Subak LL, Whitcomb E, Shen H, Saxton J, Vittinghoff E, Brown JS (2005) Weight loss: a novel and effective treatment for urinary incontinence. J Urol 174:190-195

25. Filiz TM, Uludag C, Cinar N, Gorperioglu S, Topsever P (2006) Risk factors for urinary incontinence in Turkish women: a crosssectional study. Saudi Med J 27(11):1688-1692

26. Hägglund D, Walker-Engström ML, Larson G, Leppert J (2003) Reasons why women with long-term urinary incontinence do not seek professional help: a cross-sectional population-based cohort study. Int Urogynecol J 14:296-304 